\title{
Jaspers on explaining and understanding in psychiatry
}

Christoph Hoerl

Draft chapter for Thomas Fuchs \& Giovanni Stanghellini (eds.) (2013): One Century of Karl Jaspers' General Psychopathology. Oxford: Oxford University Press.

In one of the later editions of General Psychopathlogy, Karl Jaspers writes that, when the book was first published, his discussion of the distinction between explaining and understanding was "greeted as something radically new, although all I had done was to link psychiatric reality with the traditional humanities" (GP, p. 302). There is not a little tension between the apparent modesty of this remark and the somewhat grandiose picture of the psychiatrist that emerges from some of the other pages of the book, where we learn, for instance, that only "a lifelong study of poets such as Shakespeare, Goethe, the ancient dramatists and such moderns as Dostoevsky, Balzac, etc." (GP, p. 314) can furnish a person with the kinds of understanding abilities called upon in psychiatry.

Related to this tension within the book, there is an optimistic, but also a rather more cynical, take one might have on why the distinction between explaining and understanding, as articulated by Jaspers, came to enjoy a great deal of influence on work in psychiatry. According to the optimistic take, that influence is due to the fact that Jaspers correctly identified a key element of psychiatric practice, and for the first time provided the conceptual resources required to give it a precise theoretical articulation. According to the cynical take, the influence is rather to be seen as a result of the flattering picture Jaspers paints of the psychiatrist as a Renaissance man, whose 
insights are as much to do with a scientific understanding of brain physiology as with "a close association with poetry and human reality at its greatest" (GP, p. 314).

In what follows, I will largely set aside Jaspers' claims about how the understanding abilities needed in psychiatry are acquired - which is where the cynical view takes its departure from - and focus instead on looking at how the optimistic view might be fleshed out. That is to say, my aim is to get clearer about what exactly Jaspers has to say about the nature of understanding abilities, and their role within psychiatry. What I want to argue is that there is some more recent philosophical work, in particular work on causation, that might be used to shed light on how exactly Jaspers thought of the distinction, but that also brings out where some of the challenges to Jaspers' position might lie.

\section{Understanding vs. explaining: the epistemic dimension}

In a key passage, Jaspers characterises the basic distinction between understanding and explaining as follows.

1. We sink ourselves into the psychic situation and understand genetically by empathy how one psychic event emerges from another. 2 . We find by repeated experience that a number of phenomena are regularly linked together, and on this basis we explain causally. (GP, p. 301)

As this passage indicates, at least part of the thought is that the understanding/explaining dichotomy marks a difference in epistemic method. Explaining, Jaspers thinks, requires repeated experience - it is achieved by "observation of events, by experiment and the collection of numerous examples" (GP, 
p. 302), which allow us to formulate general rules and theories. Understanding, by contrast, is achieved (if it is achieved) directly upon confrontation with a particular case. As Jaspers also puts it, "[p]sychological understanding cannot be used mechanically as a sort of generalized knowledge but a fresh, personal intuition is needed on every occasion" (GP, p. 313). We might thus say that Jaspers subscribes to a form of epistemic particularism regarding understanding. Understanding is not achieved by bringing certain facts under general laws established through repeated observation. Rather, the grasp it delivers of how one psychic event emerges from another in a particular case strikes us "as something self-evident which cannot be broken down any further" (GP, p. 303).

Jaspers is careful, though, to distinguish between this self-evidence of understanding and epistemic certainty. The immediacy with which it strikes us as intelligible that certain psychic connections obtain in a particular case should not be mistaken for a proof that they do in fact obtain. He illustrates this with the example of Nietzsche's Genealogy of Morality (Nietzsche, 1994). Genealogy too, as used by Nietzsche, engages the faculty of understanding. As Jaspers writes, "[w]hen Nietzsche shows how an awareness of one's weakness, wretchedness and suffering gives rise to moral demands and religions of redemption, $[\ldots]$ we experience the force of his argument and are convinced" (GP, p. 303). Yet, this is compatible with the possibility that the account Nietzsche provides of the "particular event of the origin of Christianity" (GP, p. 303) is in fact false. Jaspers marks this point with a terminological distinction that can be seen to mirror the distinction between knowledge and belief: Just as there can be mere belief, falling short of knowledge, we can also fall short of genuine understanding, even though we may not realize that we 
are doing so. ${ }^{1}$ In such cases, as Jaspers puts it, all we have is an interpretation of the circumstances.

The distinction between genuine understanding and mere interpretation, as Jaspers conceives of it, plays a key role in the way in which he positions himself with respect to Freud. On Jaspers' reading of Freud, the latter uses theoretical constructs modelled on understandable relationships to postulate unconscious mental states that are supposedly responsible for the patient's conscious beliefs, desires and feelings. For Jaspers, there are at least two things wrong with this methodology. First, it blurs the epistemic distinction between understanding and explaining. Understanding is treated as though it yielded knowledge of general causal laws - in particular, laws that can also operate outside consciousness. Second, and as a consequence, this methodology can at best be said to yield “"as if” or pseudo-understanding” (GP, p. 307, compare also p. 539). By Jaspers' lights, Freud can at best be seen to be offering mere interpretations, rather than genuine understanding. We might also put the point here by saying that, from Jaspers' perspective, Freud's approach ultimately involves a form of fictionalism. ${ }^{2}$ Rather than making genuine assertions about his patients' mental life, Freud in fact engages in a form of pretense. Doing so may not be completely without purpose: Imagining that the patient has the kinds of propositional attitudes Freud postulates may provide a useful tool in organizing observations and deriving predictions of their behaviour. However, this is insufficient reason for thinking that it is actually true that the patient in fact has those propositional attitudes, or that we are being provided with a genuine insight into what it actually is about the patient him- or herself in virtue of which they behave the way they do.

\footnotetext{
${ }^{1}$ See also Wiggins \& Schwartz, this volume, MS p. 12.

${ }^{2}$ See Yablo (2001) for a discussion of various forms of fictionalism.
} 
Conversely, a crucial aspect of Jaspers' construal of understanding is that understanding, when it is achieved, is factive: it does not just amount to a useful tool; it captures an objective fact of the matter about the patient's mental life. As Jaspers puts it, its role is to "make[] something visible to our experience" (GP, p. 312). Moreover, understanding, as Jaspers conceives of it, is capable of playing that role because it deals specifically with connections between elements of a person's conscious life. What makes it possible to 'sink ourselves into the psychic situation' of the other is that, to put it in more recent terminology, there is something it is like to be in that situation. Grasping what it is like for the other, however, can also make intelligible how the psychic situation they find themselves in may give rise to certain other psychological phenomena. ${ }^{3}$ Or so the thought goes.

\section{2. 'Meaningful connections': the ontological dimension}

Jaspers also casts his disagreement with Freud in terms of the idea that " $[\mathrm{t}] \mathrm{he}$ falseness of the Freudian claim lies in the mistaking of meaningful connections for causal connections" (GP, p. 539). This points to a second dimension the distinction between understanding and explaining has for Jaspers. We have already seen that this distinction, as Jaspers conceives of it, is in part a distinction on the epistemic level. However, there is also, for him, an ontological dimension to the distinction. In other words, it is not just that understanding and explaining involve two different ways of gaining knowledge; what they provide us with knowledge of is also different.

\footnotetext{
${ }^{3}$ Jaspers acknowledges that there may be factors of the patient's psychic situation that are unnoticed by the patient himself, and that understanding may require realizing how such factors can be present in consciousness albeit being unnoticed. But he insists that being unnoticed, in this sense, needs to be clearly distinguished from being extra-conscious (GP, p. 306).
} 
Meaningful psychic connections is the term Jaspers uses to describe that which understanding provides us with knowledge of. Explaining, by contrast, establishes rules of causality (GP, p. 304).

What exactly are meaningful connections, for Jaspers? As can be seen from the passage quoted at the beginning of this section, he sometimes writes as if they must, in some sense, be non-causal ones (see also, e.g., GP, p. 28). Yet this claim is quite difficult to make sense of. One problem here is that, if meaningful connections were really non-causal, it would make it quite obscure what genuine epistemic gain understanding could deliver. Adolf Grünbaum makes this point by distinguishing between causal connections and mere 'thematic affinities' between psychic events. Thematic affinities between two psychic events may make it possible for us to draw, in our own minds, a connection between them. Yet, this does little to establish the existence of an objective connection between them also within the mental life in which they occur. As Grünbaum puts it:

$[\mathrm{N}]$ arratives replete with mere hermeneutic elucidations of thematic affinities are explanatorily sterile or bankrupt; at best, they have literary and reportorial value; at worst they are mere cock-and-bull stories (Grünbaum, 1990, 575f.) ${ }^{4}$

\footnotetext{
${ }^{4}$ Grünbaum takes himself to be criticising Jaspers and his followers here, but I think it is arguable that Jaspers was in fact very much aware of the difference between a mere thematic affinity and a genuine connection between aspects of a person's psychic life. See, e.g., Jaspers, 1913, p. 178, and also the discussion below.
} 
Thus, it seems that, if understanding is to yield any genuine epistemic gain, it must be concerned with more than just thematic affinities. It must be concerned with what is actually causally responsible for the specific psychic state that the patient is in. ${ }^{5}$

There is also a second, exegetical, problem with the idea that meaningful connections, as Jaspers conceives of them, are non-causal ones. On the face of it, much of what Jaspers himself writes about them, and about understanding, seems incompatible with this idea. Consider, for instance, the following passage.

Psychic events 'emerge' out of each other in a way which we understand. Attacked people become angry and spring to the defence, cheated persons grow suspicious. (GP, p. 302)

What Jaspers describes as 'emergence' here clearly goes beyond the mere idea of a thematic affinity, as articulated by Grünbaum. And, arguably, it does so precisely because the relevant notion of 'emergence' at issue here is a causal one. There are also other terms Jaspers uses when describing examples of meaningful connections such as 'reacting', or 'growing out of' - which are difficult to understand as anything other than causal terms.

It therefore makes sense to see whether there is a way of construing what Jaspers is trying to get at that is compatible with the thought that understanding, like explaining, deals with connections that are ultimately to be thought of in causal terms, even though the two don't deal with exactly the same (type of) connections. I think we can see how this might be done if we look at a concrete example he uses to illustrate the idea of an understandable connection. He writes:

\footnotetext{
${ }^{5}$ Compare also Jaspers' distinction between understanding and mere interpretation, as discussed above.
} 
[T]he frequency of the understandable connection between autumn and suicide is not confirmed by the suicide-curve, which shows a peak in the spring. This does not show that the understandable connection is wrong since one actual case can furnish us with the occasion to establish such a connection. (GP, p. 304)

The specific point Jaspers seems to be making here is that there can be an understandable connection, in a particular case, between one factor, A, and a certain event $\mathrm{E}$, even if, in general, that type of event is less likely to occur in the context of A than it is in the context of another factor, B. Straight off, it should be obvious that this point does nothing to undermine the idea that the relation between $\mathrm{A}$ and $\mathrm{E}$ is a causal one. ${ }^{6}$ However, a point of this kind is sometimes made in the context of arguing for a distinction between two different types of causal claims, viz. what are sometimes called singular causal claims (e.g., David's taking paracetamol caused him to have a headache) and general causal claims (e.g., Taking paracetamol causes headaches), respectively. ${ }^{7}$ How exactly this distinction is to be construed is vigorously debated in the philosophical literature on causation, but there is one particular construal of it that in fact displays striking affinities with some of the remarks Jaspers makes about the distinction between understanding and explaining. On this construal, singular causal claims are in some sense more fundamental in capturing the real nature of the relation between causes and their effects, and general causal claims are

\footnotetext{
${ }^{6}$ For some material on the relationships between causation and probability that is relevant here see, e.g., Cartwright (1979), Hitchcock (1995).

${ }^{7}$ See, e.g., Sober (1985).
} 
mere generalizations over singular ones. This kind of view, sometimes referred to as singularism about causation, has been defended by Elizabeth Anscombe, who writes:

[C]ausality consists in the derivativeness of an effect from its causes. This is the core, the common feature, of causality in its various kinds. Effects derive from, arise out of, come of, their causes. [A]nalysis in terms of necessity or universality does not tell us of this derivedness of the effect; rather, it forgets about that. (Anscombe, 1981, p. 136)

Against the background of a view such as Anscombe's, we might understand Jaspers' view as follows. When he talks about (mere) causal explanation, what he has in mind are general causal claims linking types of events. Understanding, by contrast, is concerned with singular causation in the psychological domain - i.e. with the particular way in which one psychic event emerges from or arises out of another on a particular occasion. Furthermore, only understanding makes manifest what causation between one element of a person's mental life and another ultimately consists in. In so far as there are true generalizations or laws in psychology at all, these obtain in virtue of the kinds of singular causal connections that understanding makes manifest. The obtaining of such generalizations or laws is not what makes it the case that one psychic event causes another on any particular occasion.

Interpreting Jaspers in this way does make it possible to preserve his idea that there is a difference in kind between what understanding provides us with knowledge of and what explaining provides us with knowledge of, whilst allowing that there is nevertheless a sense in which they are both dealing with causal relationships. It also has the added virtue of helping to bring into focus a particular challenge Jaspers faces. 
For there is considerable opposition in contemporary philosophical work on causation to the kind of approach advocated by Anscombe. I will discuss one expression of such opposition in the next section, and then consider the bearing it might have on how exactly we should understand Jaspers' view.

\section{The 'level' of understanding}

That mental phenomena be amenable to understanding is important to Jaspers for a specific reason. For he thinks that it is in fact constitutive of mental phenomena that they do stand in meaningful connections to each other, and it is understanding that uncovers such meaningful connections. Any attempt to approach the mental merely by bringing it under causal laws, by contrast, ends up "losing the object of the enquiry" (GP, p. 302). ${ }^{8}$

The basic intuition here is familiar from other writers. It shows up, for instance, in the following passage, in which Christopher Frith argues that delusions such as thought insertion have to be accounted for 'at the right level'.

$[C]$ onsider statements of the type 'alien thoughts are caused by inappropriate firing of dopamine neurones'. Let us assume that it is true that there is an association between alien thoughts and abnormal dopamine neurones. Nevertheless, the explanation is clearly inadequate. It says nothing about the nature of the [delusion] and the processes that underlie [it]. (Frith, p. 26).

\footnotetext{
${ }^{8}$ See Eilan (2000) for further discussion of this ingredient of Jaspers' view, and also Sass, this volume (MS pp. 13ff.), for a connected critique of Jaspers' characterization of 'phenomenology'.
} 
The general idea in the background here is of a hierarchy of different possible levels of description, such as the physical, biological, and psychological, each featuring a specific set of variables. And the more specific claim is that accounting, e.g., for psychological phenomena and their specific nature requires linking them to other variables on the same level, i.e. the psychological level.

A particularly influential version of this latter claim can be found to be at work in authors such as Davidson and Dennett, who claim that ascribing propositional attitudes such as beliefs, desires and intentions to a person is a matter of rationalization, i.e. of making rational sense of particular beliefs, desires or intentions in light of the person's other propositional attitudes and the situation they find themselves in. ${ }^{9}$ Fleshed out in this way, though, the idea that psychological phenomena must be accounted for 'on the psychological level' might in fact be seen to have paradoxical consequences when it comes to psychopathology. For it seems to force upon us a choice between two ways of treating phenomena such as delusions, neither of which seems plausible. Either they would have to be seen as responses that, despite appearances, can in fact be made good rational sense of, say, given certain unusual experiences. Or we would have to say that, despite appearances, the patient does not in fact hold the bizarre beliefs they seem to report.

Already from the point of view of common sense, this seems a false choice. ${ }^{10}$ The possibility of an illness that befalls our rational endowment, whilst leaving intact the basic capacity to have beliefs and desires, seems all too real. Especially from the

\footnotetext{
${ }^{9}$ Cf., e.g., Davidson (1980) and Dennett (1987).

${ }^{10}$ Which is not to say that there haven't been attempts to argue that one of those two choices mentioned above is in fact correct. Thus, Maher (1988) adopts what is in effect a version of the former view, whereas Berrios (1991) opts for the latter. Compare also Evnine (1989).
} 
standpoint of the psychiatrist, though, it appears obvious that such cases actually exist. Led by considerations such as this, John Campbell has argued against both the general idea of a 'psychological level' on which psychological phenomena have to be accounted for, and the more specific idea that ascriptions of propositional attitudes is necessarily a matter of rationalization. For Campbell, both ideas in fact rest on the same mistake, which lies in the thought that causal connections must possess a certain form of intelligibility. He writes:

We naturally seek a certain kind of intelligibility in nature; we naturally try to find explanations that will show the world to conform to reason, to behave as it ought. Hume's point is that there are no such intelligible connections to be found. This point has generally been accepted by philosophers thinking about causation. [...] Hume's comments nonetheless do leave us in an uncomfortable position, because we do tend to look for explanations that make the phenomena intelligible to reason. We are prone to relapse, to think that after all we must be able to find intelligibility in the world. This tendency survives, I suspect, in the idea of 'levels of explanation'. The idea is that within certain levels of explanation, we will find a particular kind of intelligibility. [T]he lesson from Hume is that there is no more to causation than arbitrary connections between independent variables of cause and effect. We have to resist the demand for intelligibility. (Campbell, 2008, p. 201)

The specific approach to causation Campbell himself subscribes to is often referred to as interventionism. One key idea behind interventionism is that causal relationships are relationships that are exploitable for the purposes of manipulation and control. Put 
very crudely, what it is for A to be a cause of E, according to the interventionist, is for there to be a way of manipulating E through manipulating A (see Woodward, 2003, for a considerably more refined articulation of this basic idea).

What causes what, on this type of view, clearly has nothing to do with intelligibility. It is simply a matter of whether certain truths hold as to what would happen if we performed certain interventions. Campbell illustrates this point with the example of research carried out by Kendler and colleagues on depression following catastrophic life events (Kendler et al. 2003). This research suggests that the best predictors amongst catastrophic life events for a subsequent occurrence of major depression are episodes of humiliation, especially humiliation with some significant social dimension. As Campbell points out, alongside this type of research also stands other research that assigns serotonin transporters a causal role in depression. Thus, the question arises how we are to think of the relationship between these two factors, that both seem to play a role in the genesis of major depression. Campbell's suggestion is that we should simply see humiliation and serotonin function as two different variables that can be "put together in a single causal account of the disorder" (Campbell, 2008, p. 205). He goes on to say:

Is there any reason why we should rule out such explanations a priori and say that they somehow involve a confounding of variables of different types? On the interventionist approach, it is difficult to see why there should be any such prohibitions. [...] Intervene on the humiliation, and there will, in some cases at any rate, be a difference in the risk of depression. Intervene on serotonin function, and there will, in some cases at any rate, be a difference in the risk for depression. Do we need any more than this to establish the legitimacy of 
the many-sorted causal explanation? Isn't it perfectly obvious that the manysorted causal account is legitimate? (Campbell, 2008, p. 205f.)

Just to make absolutely explicit what the issues at stake here are, note two implications of the view Campbell sketches here. First, whilst in the example Campbell uses there is both a psychological cause (the humiliation) and a biological one (the serotonin), there is in fact nothing in his view that guarantees that there must be at least some factors 'on the psychological level' amongst the causes for any given psychological phenomenon. In interventionist terms, there may simply be no other psychological variable interventions on which would make any difference to a given aspect of a subject's psychic life. Second, there is, on this view, also no reason to think that causal links within the psychological domain need to be intelligible. As long as the right kind of interventionist counterfactuals hold between two mental states, the first one can causally explain the second one, irrespective of whether there are any intelligible connections between them. This is in fact what, according to Campbell, happens in psychosis. As an example, he uses the case of delusions of reference. He says:

[On my] analysis, for one belief to be the cause of another is for intervening on the first belief to be a way of changing the second. Suppose you believe:

(1) that this man is stroking his chin, and

(2) that this man believes you need a shave.

[...] What is it for the first belief to be a cause of the second? On the interventionist analysis, it is for intervention on the first belief to be a way of changing whether you have the second belief. So if some external force 
changed your belief that this man is stroking his chin, you would no longer believe that he believes you need to shave. (Campbell, 2009, p. 143)

What we have here, then, is a view of causation, and of causal explanation in psychology, that is radically at odds with the thought that, in order to spell out what it is for two psychic events to be causally connected in the first place, we have to appeal to the idea that such events " "emerge' out of each other in a way which we understand" (GP, p. 302). As such, it is also at odds with the reading of Jaspers' distinction between explaining and understanding that I have offered in the preceding section, which turned on this thought. On Campbell's view, the idea of a 'meaningful connection' plays no essential role in accounting for causation between psychic events. Moreover, Campbell thinks that we have to abandon the thought that it does so precisely in order to do justice to the very idea of psychopathology - of a mental life marked by an impairment to one's rational endowment.

\section{A third position?}

How might Jaspers respond to the kind of argument Campbell puts forward? Perhaps we can make a start on this issue by looking again at the two examples Campbell actually mentions. Arguably, in each of the two cases, there is in fact still a sense in which understanding can get some kind of grip. What they might not involve is a transition between mental states that can be fully explained in terms of rules of rationality. But it is also not true that we have no idea how humiliation might give rise to some of the patterns of thought and feeling characteristic of depression, or how one might read a message about one's needing a shave into seeing someone else stroke his chin. What this shows is that our common sense notion of understanding encompasses 
more than the idea of rationalization. Common sense, in other words, finds a form of intelligibility in connections between mental phenomena that is not just a matter of rational intelligibility. Indeed, for Jaspers, psychology, properly speaking, only starts when we engage in a type of understanding that goes beyond a mere grasp of rational connections. He writes:

Rational understanding always leads to a statement that the psychic content was simply a rational connection, understandable without the help of any psychology. Empathic understanding, on the other hand, always leads directly into the psychic connection itself. Rational understanding is merely an aid to psychology, empathic understanding brings us to psychology itself. (GP, p. 304)

We can think of Jaspers' position here as one that tries to establish an alternative to both the kind of view exemplified by Davidson and Dennett, on the one hand, and Campbell's view, on the other. Jaspers does subscribe to a 'levels of explanation' approach of the kind Campbell wants to abandon, in so far as he thinks that it is constitutive of psychic phenomena that they stand in meaningful connections with each other, which can (at least to a certain extent) be uncovered through understanding. Giving up the idea that there is thus a specific way in which psychic phenomena can be made intelligible would mean "losing the actual object of the enquiry" (GP, p. 302). Yet, contrary to Davidson and Dennett, the relevant type of intelligibility here has to be distinguished from mere rational intelligibility.

This, however, gives us only an extremely schematic picture of Jaspers' position, and it has to be said that some interpretative effort is required to extract from 
General Psychopathology materials that might help to flesh it out in more concrete terms. In the book, Jaspers' initial theoretical characterization of the distinction between explaining and understanding is followed by a number of examples of what Jaspers takes to be types of meaningful connections. In this context, he makes use, for instance, of a Nietzsche-inspired notion of drives, or the idea of opposing tendencies that psychic life is always subject to. But, even setting aside the question as to whether these constitute psychological categories in good standing, it is very difficult to distil a systematic picture out of Jaspers' discussion that would help make clearer, e.g., how exactly he might respond to the type of argument put forward by Campbell.

Perhaps a better source for material that might help us flesh out Jaspers' position is an article, also published in 1913, which starts with close variants of the more programmatic remarks on the distinction between understanding and explaining that can be found in General Psychopathology. In contrast to the book, however, the article follows up these remarks with two extremely detailed case studies, each including an 'analysis' containing sub-sections that are explicitly identified as dealing with causal and meaningful connections, respectively.

What emerges from Jaspers' discussion of the two cases as issues to be addressed as a matter of (mere) causal explanation is whether (and to what extent) the psychosis was, for instance, caused by imprisonment or homesickness, or by an innate 'hysterical constitution', or whether it reflects a pathological process of the type that is characteristic of schizophrenia (Jaspers, 1913, pp. 203f.). Much of what Jaspers writes here in fact fits in quite well with an interventionist approach to causation, in so far as it involves identifying particular non-psychic variables in play in each case. Specifically, Jaspers seems to think that we can identify which particular kind of such variable is in play because they make a difference to the particular form the psychosis 
takes. Thus, for instance, hysterical psychoses are characterized by a clouding of consciousness and often have a theatrical aspect, whereas schizophrenic psychoses don't have these features. Yet, there is also a respect in which, even here, Jaspers' interest can be seen to go beyond merely identifying particular causally relevant variables. What he also seems to be interested in is what we might refer to as the ontology of the non-psychic factors that made a particular psychotic episode possible: are they themselves episodic, do they exist in the form of something like a standing disposition, or in the form of an unfolding process?

Jaspers provides the most detailed discussion of what, by contrast, he regards as meaningful connections in connection with the case of 'Joseph Mendel'. In particular, one central claim he puts forward is that Mendel's psychosis can be understood, in part, against the background of a general sceptical disposition, understood as a lack of an ability to form firm opinions. This, Jaspers believes, leads to a preoccupation with philosophy - a "metaphysical need" (ibid., p. 253) or "need for a system" (ibid.). Yet, once Mendel actually starts to study philosophy, prompted by this need, the study of philosophers such as Kant, Brentano and Husserl just reinforces the feeling that nothing can be asserted with any confidence.

Can an example such as this help to clarify how exactly understanding, according to Jaspers, can lend intelligibility to psychoses, and what kind of intelligibility might be at issue? Jaspers does stress in connection with both of the case studies that understanding of meaningful connections in psychosis can only ever be achieved to a degree (ibid., p. 257). To the extent that it can be achieved, though, the kind of understanding Jaspers has in mind seems to be especially connected to notions such as 'psychic upheaval' or 'psychic disintegration', where these have mainly to do with aspects of the mental such as fears, wishes and motivation. Thus, 
for instance, Jaspers says of Mendel that he didn't suffer from intellectual defects, but that his psychoses rather have to be understood against the background of changes to the 'life of the will' (Willensleben) and his values (ibid., p. 258).

On one possible reading, what Jaspers might be seen to be drawing attention to in these passages are features of human psychology that are simply left out by the idea of the mind as governed purely by principles of rationality, but that, in turn, have some bearing on the extent to which the subject can be rational. For instance, as Jon Elster (1985) has pointed out, whilst a given set of evidence may make it rational to form a certain belief, the question as to when he or she should stop collecting further evidence is not ultimately one the subject can answer purely by relying on principles of rationality. Whilst the subject "knows, from first principles, that information is costly and that there is a trade-off between collecting information and using it, $[\ldots]$ he does not know what that trade-off is" (Elster, 1985, p. 69). As a consequence, even within the context of rational deliberation, the subject has to rely on "shadow decisions" (Elster, 1985, p. 69) as to when to stop collecting evidence, which cannot themselves be accounted for purely rationally.

So we might conjecture that understanding, for Jaspers, in so far as it is to be contrasted with or go beyond mere rationalizing, is in fact concerned with features of psychology of the latter type, that are in some sense preconditions for, and constraints on, rational thought. In this category we might further include, for instance, the conditions under which certain thoughts occur to us in the first place, or come to occupy us, or indeed become difficult to shake off despite some evidence to the contrary. Intuitively, it does seem that we have at least some idea, from our own case, how other psychic factors can have an impact on these features so that we become, for instance, more prone to jumping to conclusions or more prone to prevaricating. And if 
this is what Jaspers means by psychological understanding, we can see how it is indeed different from purely rational understanding, and perhaps also how it might be thought to have a special role to play in psychiatry. The thought, in short, would be that it is an understanding of this type that must be brought into play if we are to get at least some grip on what psychic illness actually consists in.

At the beginning of General Psychopathology, Jaspers characterizes the concept of psychic illness as being concerned with cases in which human beings' distinctive "freedom and infinite possibilities are themselves a cause of illness" (GP, p. 8). If what I have been saying is along the right lines, we might see Jaspers as signalling here that, as long as we focus only on the notion of rationality, or of an absence of rationality, we will not get a proper grasp of what it is for someone to have a psychic illness. Rationality is impaired in psychic illness, but not every case of impaired rationality is a case of psychic illness. Rather, to get right the specific nature of psychic illness, we have to bring in the idea of a specific way in which rationality is affected in psychic illness. And what makes that idea available is the thought that rational thought is itself dependent on, and constrained by, other cognitive and volitional preconditions that are not themselves a matter of rational decision. In psychic illness, particular features of the patient's psychic situation affect these preconditions to such an extent that the very capacity for rational thought is impacted upon. However, even outside the context of psychic illness, the particular shape and content of a person's psychic life is never dictated by purely rational considerations alone. And we can therefore have at least some insight, from our own case, into the general kind of 'emergence' of constraints on one's mental life from features of one's psychic situation that, in psychosis, leads to a pathology. 


\section{The ununderstandable in schizophrenia}

Having sketched one possible interpretation of Jaspers' views on understanding and its role in psychiatry, I want to finish with a few remarks about a particular type of limit to understanding Jaspers talks about specifically in connection with schizophrenia.

Psychology will always come up against limits where understanding, as Jaspers conceives of it, is no longer possible. In most of General Psychopathology, the understandable is set off against the ununderstandable primarily in the guise of that which falls outside the contents of consciousness. As Jaspers says, "the act of understanding presupposes and implies something that cannot be understood" (GP, p. 308). This is true, he thinks, in two quite different senses. First, our mental life is shaped by the particular nature of our embodied existence and our interactions with our environment. These condition the contents of our consciousness causally from outside. Secondly, the very existence of a conscious life itself is also something that falls outside the scope of possible understanding. ${ }^{11}$ Understanding can only encompass meaningful connections within consciousness; it cannot illuminate the conditions of the possibility of its own existence.

In a small number of passages in the book, though, the ununderstandable also appears in a further, somewhat different guise - in the context of the idea that, in schizophrenia, some aspects of the patient's conscious mental life itself become in principle ununderstandable. Jaspers writes:

The most profound distinction in psychic life seems to be that between what is meaningful and allows empathy and what in its particular way is

\footnotetext{
${ }^{11}$ This, at any rate, is one way of understanding some of the more enigmatic remarks at GP, p. 308.
} 
ununderstandable, 'mad' in the literal sense, schizophrenic psychic life. (GP, p. 577)

The idea of the ununderstandable, in the specific sense at issue here, is meant to capture a sense in which certain schizophrenic symptoms are particularly puzzling. For it is to be distinguished from the idea that, in any concrete situation, there will be limits to understanding beyond which only interpretation is possible. The latter idea has to do with how much detailed information we possess about the patient. By contrast, Jaspers seems to think that there is something in principle ununderstandable about schizophrenic psychic life. Yet, at the same time, schizophrenic ununderstandability also has to be contrasted with cases in which, as we might say, there is really nothing left that calls for understanding. Jaspers makes this point by using the example of general paralysis and contrasting it with that of schizophrenia.

In the one case, it is as if an axe had demolished a piece of clockwork - and crude destructions are of relatively little interest. In the other it is as if the clockwork keeps going wrong, stops and then runs again. In such a case we can look for specific, selective disturbances. But there is more than that; the schizophrenic life is peculiarly productive. (GP, p. 576f.)

What Jaspers seems to have in mind here is that there is a sense in which the schizophrenic ununderstandable calls for understanding at the same time as precluding it. Schizophrenia, by contrast with general paralysis, is productive of genuine mental phenomena and - in line with Jaspers' position as sketched in sections 3 and 4 , above - it is in fact constitutive of such mental phenomena that they stand in 
meaningful psychological connections to other aspects of the patient's mental life. But there is a particular feature of the mental phenomena produced in schizophrenia that, at the same time, stands in the way of us being able to uncover the relevant meaningful connections through understanding.

Is there a way of fleshing out this line of thought in more concrete terms? I think the kind of interpretation of Jaspers I have offered might help us see a way to do so, especially once we note that there is one specific 'productive' aspect of schizophrenic life, in particular, that Jaspers seems to have in mind when he talks about the schizophrenic ununderstandable. These are what he refers to as 'made phenomena', such as thought insertion. Against the background of the reading of Jaspers' position I have offered above, we can perhaps see why he would find such phenomena particularly puzzling. For what is remarkable about them is that the patients in fact think of their own mental lives in the interventionist way suggested by Campbell: as being potentially manipulable by any variable whatsoever (even without any involvement of the rest of their own psyche). And this may be seen to make any attempt at understanding them a particularly paradoxical endeavour. On the one hand, to attempt to understand them, in the way envisaged by Jaspers, means that we must suppose that the patient's attitude towards their own thoughts somehow emerges from other, prior, aspects of their psychic life. Yet, actually 'sinking ourselves into the psychic situation' of the patient in fact means giving up, within the project of trying to understand the patient, on this very conception of psychic states as emerging from in each in a meaningful way. Thus, in schizophrenia, the content of the delusion that we 
are trying to understand - the idea of a 'made' mental life - conflicts with the very conception of the mental that governs the project of emphatic understanding. ${ }^{12}$

${ }^{12}$ Thanks to the members of the Wednesday philosophy of mind discussion group at Warwick for a number of very helpful comments. I am also grateful for additional written comments I received from Eileen John and an anonymous reviewer. 


\section{References}

Anscombe, G.E.M. (1981). Causality and determination. In: Metaphysics and philosophy of mind. Collected philosophical papers II. Oxford: Basil Blackwell.

Berrios, G.E. (1991). Delusions as 'wrong beliefs': A conceptual history. British Journal of Psychiatry 159, pp. 6-13.

Campbell, J. (2008). Causation in psychiatry. In: K.S. Kendler and J. Parnas (eds). Philosophical issues in psychiatry. Baltimore: Johns Hopkins University Press.

Campbell, J. (2009). What does rationality have to do with psychological causation? Propositional attitudes as mechanisms and as control variables. In: L. Bortolotti and M. Broome (eds). Psychiatry as cognitive neuroscience. Oxford: Oxford University Press.

Cartwright, N. (1979). Causal laws and effective strategies. Noûs, 13, pp. 419-437.

Dennett, D. (1987). True believers. The intentional strategy and why it works. In: The intentional stance. Cambridge, MA: MIT Press.

Eilan, N. (2000). On understanding schizophrenia. In: D. Zahavi (ed.). Exploring the self: Philosophical and psychopathological perspectives on self-experience. Amsterdam: John Benjamins.

Elster, J. (1985). The nature and scope of rational-choice explanations. In: E. LePore and B.P. McLaughlin (eds.). Actions and Events: Perspectives on the philosophy of Donald Davidson. Oxford: Blackwell.

Evnine, S.J. (1989). Understanding madness? Ratio 2, pp. 1-18 
Frith, C.D. (1992). The cognitive neuropsychology of schizophrenia. Hove: Lawrence Earlbaum Associates.

Grünbaum, A. (1990). 'Meaning' connections and causal connections in the human sciences. Journal of the American Psychoanalytic Association 38, pp.559577.

Hitchcock, C. (1995). The mishap at Reichenbach fall: Singular vs. general causation. Philosophical Studies 78, pp. 257-291.

Jaspers, K. (1997). General Psychopathology, trans. J. Hoenig \& M.W. Hamilton. Baltimore, MD: Johns Hopkins University Press. (cited as 'GP' in the text)

Jaspers K. (1913). Kausale und verständliche Zusammenhänge zwischen Schicksal und Psychose bei der Dementia praecox (Schizophrenie). Zeitschrift für die gesamte Neurologie und Psychiatrie 14, pp. 158-263.

Kendler, K. S., Hettema, J. M., Butera, F., Gardner, C. O., \& Prescott, C. A. (2003). Life event dimensions of loss, humiliation, entrapment, and danger in the prediction of onsets of major depression and generalized anxiety. Archives of General Psychiatry 60, pp. 789-796.

Maher, B.A. (1988). Anomalous experience and delusional thinking: The logic of explanations. In T.F. Oltmanns and B.A. Maher (eds). Delusional Beliefs. Chichester: John Wiley and Sons, pp. 15-33.

Nietzsche, F. (1994). On the genealogy of morality, trans. C. Diethe. Cambridge: Cambridge University Press. 
Sober, E. (1985). Two concepts of cause. In P. Asquith and P. Kitcher (eds.). PSA 1984, Volume II. East Lansing: Philosophy of Science Association, pp. 40524.

Woodward, J. (2003). Making things happen: A theory of causal explanation. Oxford: Oxford University Press.

Yablo, S. (2001). Go figure: A path through fictionalism. Midwest Studies in Philosophy 25, pp. 72-102. 